\title{
O ARMÁRIO COMO QUESTÃo DE GÊNERO PARA A GESTÃo PEDAGÓGICA: A PEDAGOGIA QUEER COMO CUIDADO DO CUIDADO DO OUTRO
}

\author{
Alan Isaac Mendes Caballero ${ }^{1}$ \\ Antonio Carlos Dias Junior ${ }^{2}$
}

\section{Introdução}

O cuidado de si é apresentado por Michel Foucault em A hermenêutica do sujeito (2006) como um conjunto de técnicas utilizadas voluntariamente pelos sujeitos para orientá-los à verdade. A análise feita pelo autor acerca desses exercícios de ascese permite ao leitor perceber as transformações que os sujeitos esperam ver realizadas em si mesmos. Ao contrário do que Foucault fez no primeiro volume de sua História da sexualidade (2015), no qual aborda as influências da austeridade sexual do período vitoriano sobre a sexualidade no século XX, concentra-se desta vez, em A hermenêutica do sujeito (como nos próximos volumes de História da sexualidade), numa história das técnicas de $\mathrm{si}^{3}$ e nas relações dos sujeitos consigo mesmos. Não é mais o poder ou o saber que estão em jogo, segundo Gros (2006), mas uma problematização sobre o sujeito capaz de produzir-se num encontro com o outro (médico, mestre, conselheiro do príncipe, diretor de consciência, amigo). Não é mais sobre sexo, pois para Foucault "sexo é chato" (FOUCAULT et al., 2013, p. 296), ou mesmo sobre práticas sexuais (não é apenas sobre práticas sexuais). Para o autor, vale mais essa relação do sujeito com a verdade por uma inclinação particular, isto é, uma decisão ética e estética do sujeito em tornar-se aquilo que convém.

A partir destas questões, este trabalho propõe operar com o conceito de cuidado de si pela metáfora da navegação nas práticas de gestão, na qual um diretor/diretora ou orientador/orientadora escolar são responsáveis pelo cuidado do outro por meio da prática da liderança, vistos em Foucault pelas relações de amizade, eróticas ou de mestre-discípulo quando estabelece a sua genealogia sobre o cuidado de si nos períodos grego, helênico e no início do cristianismo. Esse cuidado de si entrevê na metáfora da navegação uma possível aliança com a metáfora já citada do ciborgue de Donna Haraway, na qual as identidades de gênero podem se justapor para serem pensadas como fluxo de desejos descompromissados com qualquer identidade final, ou ainda, na afinidade política dos corpos em suas relações estéticas pelas coisas corporais (ROLNIK, 2005).

Dentre as muitas preocupações do gestor escolar, identificamos o prazer da criança, sobretudo naquilo que representa o seu desejo e como este vem a expressar-se no interior da escola, já que a orientação sexual é um dos temas transversais dos Parâmetros Curriculares Nacionais (BRASIL, 1997). Ademais, isto nos permite prever a existência de currículos comprometidos com as questões relativas às relações de gênero e problematizações sobre sexo - sempre tendo em vista a relação entre a gestão escolar e as políticas educacionais, e admitindo-

\footnotetext{
${ }^{1}$ Mestrando em Educação (FE-Unicamp). Licenciado em Pedagogia (FE-Unicamp, 2017). E-mail: alanisaac09@gmail.com. ${ }^{2}$ Doutor em Sociologia (IFCH-Unicamp, 2013). Professor do DECISE-FE-Unicamp - Campinas-SP. E-mail: acdiasjr@unicamp.br.

${ }^{3}$ Alguns autores utilizam “práticas de si”, como é o caso de Frédéric Gros (2006), ao contrário de "técnicas de si”, como o fazem Dreyfus e Rabinow (2013). Em todo caso, escolheu-se o primeiro termo por ele remeter à thékne, que também significa arte. É igualmente importante pela relação que possui com tecnologia, palavra destacada para sugerir a metáfora do ciborgue de Donna Haraway (2009).
} 
a como práticas de tradução, uma vez que a política pode ser realizada de maneira divergente, dados os condicionantes das normas legais, daquela que seu legislador a pensou. ${ }^{4}$

\section{O papel pedagógico do gestor escolar}

Antes de avançarmos na discussão, devemos colocar em relevo a posição do gestor escolar para, daí, rumarmos à problematização curricular. Tomemos como exemplo introdutório alguns registros de indisciplina de uma escola brasileira. Alguns desses relatórios foram escritos por diretores. Segue-se um percurso de infrações cometidas por dois alunos, um deles de 12 anos, na condição de aluno matriculado na escola, e outro de 14 anos, ex-aluno da mesma unidade: ambos pulam o muro, agem de forma agressiva com a direção, um deles desnuda-se diante de todos os presentes (deixando a genitália exposta) e incentiva o mais novo a fazer o mesmo $^{5}$. No que consiste exatamente essa indisciplina?

Podemos responder a esta pergunta partindo de duas pesquisas sobre gestão. A primeira, de Coelho (2015), apresenta as seguintes situações problemas, levantadas a partir de grupos focais divididos entre gestão escolar e professores, que discutiam os seguintes tópicos: a) relações da escola com a família; b) desamparo pedagógico dos professores pelos coordenadores pedagógicos; c) descontinuidade da prática docente; d) imprecisão no gerenciamento escolar; e) indisciplina do aluno. O papel do gestor escolar está localizado entre as esferas institucional e interpessoal, porém, os autores indicam uma lógica de distanciamento entre essas duas esferas na atividade do gestor escolar. A esfera institucional é privilegiada em relação à esfera interpessoal. As preocupações dos educadores nos grupos focais concentramse no ensino do Letramento e da Matemática. Sabe-se também que os assuntos disciplinares exigem maior dedicação de toda a equipe escolar em cumprir com as exigências de ensino.

$\mathrm{Na}$ segunda pesquisa, de Moreira e Barbosa (2017), é apresentado um estudo sobre os desafios na gestão escolar de escolas municipais brasileiras a partir de 71 banners produzidos por gestores. $57 \%$ deles consideram problemas na gestão aqueles "voltados para a potencialização do planejamento docente e avaliação de aprendizagem do aluno", isto é, problemas de gestão pedagógica (MOREIRA; BARBOSA, 2017, p. 271). A pesquisa diferencia seis tipos de gestão: a) gestão pedagógica; b) gestão democrática; c) gestão de pessoas; d) gestão financeira; e) gestão de resultados; e f) gestão de materiais e patrimônio. Ainda sobre a gestão pedagógica, 3\% desses gestores acusam a estrutura do currículo como um desafio para o seu trabalho.

Retornando os casos de indisciplina trabalhados por Ferrari e Almeida (2012), os autores relatam um enquadramento nos relatórios analisados, isto é, há certa padronização do sujeito que cumpre com os requisitos para ser denominado indisciplinado. Em suas próprias palavras, "parece haver uma constante necessidade de descrever ações e estabelecer conexões entre determinados lugares, ações e discursos" (FERREIRA; ALMEIDA, 2012, p. 873). Logo, compreendemos que os alunos enquadrados como indisciplinados são meninos, e que os relatórios analisados pelos autores aliam indisciplina à masculinidade, práticas incentivadas aos meninos, enquanto a disciplina corresponde à feminilidade, prática incentivada às meninas.

\footnotetext{
${ }^{4}$ Utilizamos o texto de Carlos Roberto Jamil Cury (2002) como fundamento inicial para pensar as atividades e responsabilidades do gestor escolar, porém com a possibilidade de traduzir o direito à educação pelo princípio da diferença e não pelo da igualdade, ao menos quando são discutidos gênero e sexualidade na organização do espaço escolar.

${ }^{5}$ Este relato é uma versão enxuta daquela exposta e problematizada por Ferrari e Almeida no artigo Corpo, gênero e sexualidade em relatórios de indisciplina (2012), no qual analisam, em uma perspectiva foucaultiana ao relacionar as categorias espaço, discurso e sujeito, o caso de indisciplina retirado dos registros de uma Secretaria de Educação, ocorrido numa unidade escolar em Juiz de Fora.
} 
Um terceiro relato, trazido de Sasso e França (2015) a partir de uma experiência com profissionais de uma escola pública brasileira que oferta Educação Infantil e Ensino Fundamental, nos traz outras pistas. Em oficinas, nas quais as pesquisadoras trabalharam temáticas como "Diversidade, gênero, sexualidade, homossexualidade, travesti, transgênero, transexual - e a importância da instituição escolar como uma das instâncias sociais a discutirem estas questões em sala de aula" (SASSO; FRANÇA, 2015, p. 91), algumas falas apontam para as tensões que perpassam a cotidianidade do trabalho de docentes e gestores.

A concepção heteronormativa pode ser apreendida a partir de falas como a de uma professora, que orientou duas crianças, após se deparar com um "selinho" entre um menino e uma menina em sua sala, "que só pode ocorrer beijo entre homem e mulher e só quando forem adultos". Para esta professora, "[...] a criança não sabia nada ainda sobre sexualidade" (SASSO; FRANÇA, 2015, p. 92), e apenas repetia comportamentos vistos em casa ou na televisão. Mais que repetir padrões heteronormativos refletidos ou irrefletidos, o exemplo deixa patente a dificuldade de professores e gestores em lidar com temas tidos como tabu, mesmo em se tratando de orientações contidas nos Parâmetros Curriculares Nacionais (BRASIL, 1997).

Portanto, questões de gênero e sexualidade são postas como desafios a serem solucionadas pela equipe escolar, defrontada a demandas institucionais de ensino avaliadas em grande escala, o que justifica o esforço da equipe escolar, nas pesquisas anteriormente apontadas, em tentar manter os alunos indisciplinados em matérias escolares como Letramento e Matemática (PERONI, 2011). Porém, cabe perguntar se problematizações sobre gênero são levadas em conta na atividade dos gestores escolares, ou mesmo se, na gestão pedagógica, a estrutura curricular promove a temática de gênero em suas discussões. Considerando os resultados obtidos por Moreira e Barbosa (2017), Sasso e França (2015) e Coelho (2015), podemos responder negativamente à questão. Assim, que tipo de currículo, que tencione a discussão de gênero, pode surgir deste trabalho de tradução de políticas educacionais em políticas escolares, das quais deriva a atividade do gestor escolar?

\section{A metáfora da navegação para a pedagogia queer}

Utilizaremos, doravante, os Estudos de Gênero para dar continuidade às problematizações. Estudos de Gênero é uma categoria ampla e diversa de áreas do conhecimento que tem por finalidade pesquisar categorias e interrelações entre sexo-gênerosexualidade tomando, via de regra, mulheres, gays, lésbicas, travestis, transgêneros, transexuais e intersexuais como objetos de pesquisa. Neste âmbito, é possível encontrar temas específicos de pesquisa, tais como Estudo de Mulheres, Estudos Queer, Estudos de Masculinidades, Estudos Gays, Estudos Lésbicos, entre outros. Os Estudos de Gênero aqui referidos mantêm proximidade com os Estudos Queer segundo a perspectiva de Guacira Lopes Louro (2001), pensados a partir de necessidades curriculares para a educação.

A maior contribuição dos Estudos de Gênero no concernente às problematizações curriculares na educação reside em diferenciar as pedagogias queer das pedagogias do armário. Por pedagogias queer compreende-se todas aquelas que desestabilizam, infletem e subvertem a dicotomia heterossexual/homossexual, cujo dispositivo permite uma educação inclusiva na qual o cuidado de si apresenta-se como o cuidado do cuidado do outro: a subjetivação não deve agir sobre a própria sexualidade ou gênero da criança, mas é permitido a ela ser aquilo que precisa ser naquele instante, podendo esse trabalho experimental que a criança faz sobre si mesma estender-se no tempo para criar uma identidade - menino, menina, homem, mulher, gay, lésbica, travesti, transgênero, homossexual, heterossexual, transexual, pansexual, assexual, por exemplo. 
Outro fator importante da pedagogias queer, além de permitir a expressão da subjetividade das crianças quanto ao seu gênero, diz respeito ao exercício repetitivo dos educadores em trabalhar o olhar de suas crianças para conviver com o queer na escola: esperase que esse respeito seja repetido também fora da escola, sobretudo para não constranger, reprimir ou incentivar intolerâncias contra o queer. Estas pedagogias, portanto, são pedagogias do devir, contrapondo-se às pedagogias do dever. $\mathrm{O}$ cuidado de si dos educadores para com as crianças acontece para sensibilizá-las a cuidarem umas das outras e a trazer para fora (na forma de ações, brincadeiras, performances, etc.) os movimentos borbulhantes do desejo e um conhecimento sobre si que apenas elas possuem e que podem fazer acontecer na sua coisa corporal - isto que está entre o desejo real do seu corpo e as possibilidades relacionais que o mundo (escola, família, etc.) lhes apresenta para tornar objetiva a sua subjetividade.

A cois a corporal é uma questão para Suely Rolnik (2005) em seu trabalho filosófico com as esculturas de Lygia Clark, pois ela suspeita que haja algo por trás do corpo da escultura, algo não evidente, não material, que dá à escultura uma corporeidade para além de um corpo talhado em pedra. Rolnik (2005) sugere, em linhas gerais, que a coisa corporal seja a relação estética entre o observador e a obra de arte. Aproveitamos para fazer a apreciação de que existe uma relação estética entre os corpos humanos para enxergar corporeidade nos corpos. Ao concebermos esta estética relacional, podemos trazer mais significados à estética da existência de Foucault, comentada em entrevista com Dreyfus e Rabinow (2013), na qual enxergamos a vida como uma obra de arte. Vemos os corpos como obras de arte perpassados por coisas corporais que dão sentido às vidas vividas. Desta perspectiva, os gestores escolares podem se apropriar desta relação estética, também presente na pedagogia queer, para desconstruir suas verdades.

Por outro lado, as pedagogias do armário, como observado, é o contraponto às pedagogias queer, e se concentram no enclausuramento do devir e na edificação do dever. Como que inspiradas no concreto e nas barras de ferro da prisão, as pedagogias do armário apresentam-se ao imaginário sob a forma de madeira: pode ser um guarda-roupa, um closet ou um simples armário rústico. Está aí para guardar segredos do sujeito na forma de um eu que não pode ou não quer se mostrar para outras pessoas. Ele/ela/elx, ao não ter vivido uma pedagogia queer ou outras experiências queer, aprende a ocultar, omitir ou esconder algo sobre si nesse dispositivo interno do armário, criado por uma rede de dispositivos externos resumidos na palavra heteronormatividade - que é nada mais que a norma heterossexual, uma prescrição de corpo, gênero e sexualidade que é demonstrada por um trabalho intenso de subjetivação sobre a criança para o seu assujeitamento à regra imposta.

Devemos observar que Foucault dedica o período final de sua produção ao estudo da sexualidade, não necessariamente a heterossexualidade ou a homossexualidade, já que esse binômio sexual aparece apenas no século XIX a partir de diagnósticos médicos, tendo sido adotadas como identidades por diversos grupos no Ocidente a partir da década de 1920, com a influência dos meios de comunicação de massa (KATZ, 1996). Em períodos anteriores, como na Idade Antiga e na Idade Média, mencionar a sexualidade em suas práticas é um anacronismo: o cuidado de si em Foucault abarca fundamentos para o dispositivo de sexualidade, mas não apenas, é um princípio de biopolítica mais geral no qual a sexualidade tornar-se-á sinônimo de heterossexualidade/homossexualidade, uma de tantas formas de controle da saúde da população.

$O$ interesse em estudar a heterossexualidade deve-se a algumas correntes feministas para as quais Foucault é uma leitura base, logo, a heteronormatividade deve ser entendida mais como uma contribuição desses feminismos do que algo original do próprio Foucault, visto que este guarda mais semelhanças com os Estudos Gays (se nos fosse dado o trabalho de classificá-lo dentro dos Estudos de Gênero) do que com os Estudos Queer, uma vez que discutir o direito à 
vida e à morte a partir da biopolítica, como visto em sua "História da sexualidade I" (2015), parecia a ele mais urgente do que elidir o binômio heterossexual/homossexual.

Sair do armário (ou ver-se defrontado a esta possibilidade) é uma tarefa angustiante e dolorosa, pois chega o momento em que o armário diminui de tamanho para não mais nele cabermos. Nesse momento, ele passa a se confundir com a nossa pele: um dispositivo que nos fragmenta e permite a produção de desejos toleráveis e incentivados. O cuidado de si nas pedagogias do armário não são o cuidado do cuidado do outro, mas o trabalho retórico de convencimento sobre a verdade, daquilo que parece ser verdade mediado pelo uso de mentiras contadas cotidianamente. Sustenta-se a norma hétero por fazer crer que ela é o princípio de tudo, a jornada espiritual de todos, a natureza comum da humanidade, e por isso, o humanismo pretendido, desejado e inescapável - isto se não resumirmos a heteronormatividade a um destino apresentado pelo sofista.

As pedagogias queer, em contraponto, seriam aquelas a utilizar a metáfora da navegação, expressada por Foucault em alguns momentos em A hermenêutica do sujeito (2006). O primeiro deles podemos ver na Aula de 17 de fevereiro de 1982, na qual navegação ilustra "deslocamento e retorno - deslocamento do sujeito em relação a ele mesmo e retorno do sujeito sobre si", cujo objetivo "é o porto, o ancoradouro, enquanto lugar de segurança onde se está protegido de tudo" (FOUCAULT, 2006, p. 302-303). Essa imagem da navegação baseia-se na ideia da pilotagem como arte (tékhne), utilizada pelo médico ao curar as almas de seus pacientes, no governante político ao dirigir seus subordinados e no governo de si mesmo. Nesse momento, Foucault pretende diferenciar as práticas platônicas de reminiscência e exegese cristãs da autofinalização presentes no período helênico (como um aperfeiçoamento de si), ao contrário da rememoração ou renúncia de si. Ao propor esta estética da existência, entende-se que Foucault contribuiu para a aproximação da metáfora da navegação como princípio de uma pedagogia queer.

A prática de reminiscência alude às pedagogias do armário no instante em que assume o aluno como um ignorante sobre suas experiências corporais, como se não pudesse dizer seu próprio gênero, e propõe cavar fundo em si para encontrar algo que esteve sempre bem escondido. Nessa lógica, temos um princípio filosófico para as práticas de confissão cristãs e para a prática de livre associação na psicanálise, as quais devem sua existência ao cristianismo (DÍAZ, 2012). Judith Butler (2017) faz um percurso crítico do desenvolvimento psíquico da identidade de gênero pela fórmula da sexuação de Lacan e por intermédio da resolução da bissexualidade em Freud, como processos decorrentes do luto e da melancolia. Neles, encontra um sentido heteronormativo para essas explicações sobre a formação do gênero na criança, já que estas duas tradições psicanalíticas apelam para a rememoração de uma perda ou de acontecimentos que parecem determinantes para o desenrolar da sexualidade (sempre heterossexual) infantil.

A renúncia de si também não se apresenta como alternativa nas pedagogias queer, visto que decorre das práticas cristãs de confissão nas quais a alma peca pela existência de um corpo, dele se libertando pela salvação em direção ao céu pela suspeita que há nele fraquezas. Deve reconhecer-se para procurar o diabo e extirpá-lo, ao contrário do encontro com o divino em si mesmo pela reminiscência. Nesse momento, o prazer é um ponto de tensão, pois será recusado, embora o desejo seja incentivado desde que direcionado a Deus pelo texto sagrado da Bíblia (DÍAZ, 2012). Quando a concepção de gênero perpassa os encontros éticos e estéticos gerados entre os corpos na formação das corporeidades, acredita-se que a renúncia de si apresenta entraves para uma pedagogia queer, podendo adequar-se a uma pedagogia do armário.

Em suma, na metáfora da navegação o sujeito pilota a si mesmo para conhecer-se, partindo de si para chegar a si. Portanto, esta viagem gera conhecimentos capazes de transformar o sujeito em sua relação com os outros. A criança pilota seu mar-desejo com os barcos que tem à disposição, dado pelas condições existenciais e por seu próprio movimento 
interno, podendo mudar de barcos por modificações nele feitas com o uso de técnicas, linguagem e brinquedos, para mencionar alguns exemplos. O desejo é intensamente trabalhado, ainda que incontrolável, pela navegação, pela trajetória da criança em si mesma, por uma cartografia das ilhas, correntes marítimas e continentes em seu próprio eu a ponto de saber quem é (ou o sujeito que, vivendo em segredo no seu corpo, possa reclamar seu eu).

Esta criança desbravadora de si mesma aprende e desaprende sobre si mesma, constrói e reconstrói seu percurso, conhece e ignora aspectos de seu mapa, o que a permite (e a nós) dizer algo sobre si. Aqui, entretanto, a criança é timoneira, encontra rochedos, tempestades e monstros marinhos. Depara-se com a fome, o frio e a solitude de seu próprio mundo. Mas, vale relembrar, estas aparições inconvenientes e estas frustrações diárias não são apenas criações espontâneas do próprio desejo inquieto da criança: são também imagens internas criadas pelas relações de afeto cotidianas. Tais imagens são a coisa corporal da criança, aquilo que diz algo sobre ela mesma pelo olhar do outro.

$\mathrm{Na}$ Aula 24 de fevereiro de 1982, encontramos a imagem do piloto como possuidor de uma paraskeué (no grego) ou instructio (no latim): "é preciso se dotar de algo que, precisamente, no lugar de nos conduzir a renunciar pouco a pouco a nós mesmos, permitirá proteger o eu e chegar até ele" (FOUCAULT, 2006, p. 387). Além do conhecimento de si, em outro momento o marinheiro deve preparar-se para conhecer o mundo. A paraskeué aparece então com o propósito de preparar alguém para a vida, e daí equipar o marinheiro para que saiba lidar com os seus acontecimentos. Ele o faz conservando discursos (logói) para serem usados em momentos de socorro (boéthos) quando encontra o perigo ou necessita de auxílio e sente perdido. O discurso é a âncora que estabiliza situações de incerteza na criança para torná-las aceitáveis através criação de comportamentos (êthos) inspirados na palavra-de-socorro dita por alguém, que funciona como prescrição e dizer-verdadeiro.

Essa perspectiva, a princípio, poderia ser situada nas pedagogias do armário, na qual os efeitos dos discursos são vistos nas performances masculinas ou femininas nas crianças que recorrem à norma hétero para o seu socorro: corpos inteligíveis, assimiláveis e percebidos como relacionáveis, ou seja, corpos vivos no mundo social à medida que a norma hétero espalha o dizer-verdadeiro (boéthos) sobre masculinidades e feminilidades visíveis e dignas de serem vividas (BUTLER, 2017). A morte ronda o marinheiro quando ele deve conhecer o mundo. O mar nem sempre é calmo; apresenta-se como tempestade e com monstros mitológicos - dizem que estão aí há incontáveis eras. O marinheiro não vence a tempestade sem curvar-se a seus caprichos, sem prever o tempo das ondas contra o casco do navio e sem prestar a atenção ao vento forte. Ele não muda o mar, é antes obrigado a mudar a si mesmo em razão deste para sobreviver e ter algo a contar quando retornar ao porto. Ele busca que outros marinheiros não possam relatar o seu insucesso, sua queda ou sua morte trágica em alto mar, nem sempre épica.

\section{Um breve comentário sobre ciborgues}

O navegante é o protagonista das pedagogias queer, nunca capitão de si mesmo, pois divide o comando de si (e talvez seja sempre obrigado a fazê-lo) com outros tripulantes. Nas pedagogias do armário, sobressaem o marujo e o náufrago. Marujo porque não é o capitão de seu navio e, inclusive, pode ter sido retirado de sua própria embarcação para servir numa tripulação de piratas saqueadores. Pode até mesmo ter sido convidado por estes mercenários a participar de outro navio, vindo de outro lugar, com uma história que não é sua, com subordinados que não conhece e não tem intimidade, mas com quem divide esse lugar comum. A identidade, porém, é incomunicável e irreconhecível. Talvez seja mesmo um náufrago, alguém numa ilha, perdido ou quem sabe preso, vendo o mar revolver-se diante de si e sem perspectivas de dali sair. 
O desejo nunca se extingue, uma vez que o mar está sempre lá para este pequeno timoneiro, marujo ou náufrago. Por sua vez, o barco e o espírito aventureiro são os objetivos da pedagogia queer, capaz de velejar em sua própria identidade com fluidez, liberdade e responsabilidade. Este mar aos poucos será o lar de outros barcos, donde surgem as parcerias, alianças e até a pirataria, todas elas formas de subjetivação. Pode surgir daí também um ciborgue, metáfora criada por Donna Haraway (2009) para superar dicotomias como mente/corpo, natureza/cultura, razão/emoção, Tecnologia/Biologia, humano/não-humano e assim por diante. A metáfora do ciborgue pode evidenciar a coisa corporal, a não-separação entre as realidades internas e externas da criança: preferimos vê-la como alguém na fronteira ou, ainda, que atravessa fronteiras para montar-se com elementos deste ou daquele território para ser, no final das contas, um território-corpo original no seu processo de montagem e desmontagem ${ }^{6}$.

A partir disto e de rumores da terra dos ciborgues, lá no além-mar, imagina-se o trabalho de gestão nas escolas praticando o cuidado de si na idade contemporânea, sobretudo nas escolas brasileiras de ensino fundamental. Mas estas terras já foram avistadas ao subir no mastro, por isso percebemos que o mapa revela um geoide no qual basta dar meia volta para chegar ao além-mar ao invés de circundar o globo. Ali, tão perto, está a prometida terra dos ciborgues, dessas máquinas que confundem o navegante com o próprio barco. Quem sabe não seja isto o corpo? Quem sabe não seja esta uma perspectiva razoável para a prática do cuidado de si numa pedagogia queer?

\section{Considerações finais}

A partir da metáfora da navegação, trazida de A hermenêutica do sujeito (2006) de Michel Foucault, sugeriu-se concepções para uma pedagogia queer desempenhada na tradução de políticas curriculares de gênero para a realidade do trabalho do gestor na unidade escolar. Nesta perspectiva, sobressaiu-se a ideia de cuidado do cuidado de si como prática pedagógica para a formação da corporeidade da criança, no qual o gênero aparece como experimentação (pessoal e compartilhada) e autoconhecimento. Também avançamos para a metáfora do ciborgue na intenção de demonstrar aspectos fictícios (embora não místicos) das fronteiras do corpo e do gênero, incentivando, assim, a não binaridade da pedagogia, bem como a importância de condições materiais e institucionais para a emergência do queer nas escolas. Para estas últimas considerações, credita-se à figura do gestor escolar a função notável de cuidar do cuidado da criança queer cuidando da escola na qual ela está inserida com o uso de uma pedagogia queer, transformando-a num porto de ciborgues-em-alto-mar.

\section{Referências}

BRASIL. Parâmetros curriculares nacionais: pluralidade cultural, orientação sexual. Secretaria de Educação Fundamental. Brasília: MEC/SEF, 1997.

BUTLER, J. Problemas de gênero: feminismo e subversão da identidade. Rio de Janeiro: Civilização Brasileira, 2017

COELHO, F. M. O cotidiano da gestão escolar: o método de caso na sistematização de problemas. Educação \& Realidade, Porto Alegre, Ahead of print, p. 1-16, 2015.

\footnotetext{
${ }^{6}$ Interessante perceber esse processo ciborgue nas brincadeiras das crianças.
} 
CURY, C. R. J. Gestão democrática na educação: exigências e desafios. Revista Brasileira de Política e Administração da Educação, São Bernardo do Campo, v. 18, p. 163-174, 2002.

DÍAZ, E. A filosofia de Michel Foucault. Tradução de C. Candiotto. São Paulo: Editora UNESP, 2012.

FERRARI, A.; ALMEIDA, M. A. Corpo, gênero e sexualidade nos registros de indisciplina. Educação \& Realidade, Porto Alegre, v. 37, n. 3, p. 865-885, set./dez. 2012.

FOUCAULT, M. A hermenêutica do sujeito: curso dado no Collège de France (1981-1982). 2. ed. São Paulo: Martins Fontes, 2006.

FOUCAULT, M. História da sexualidade 1: a vontade saber. Tradução de M. T. C. Albuquerque e J. A. G. Albuquerque. 2. ed. São Paulo: Paz e Terra, 2015.

FOUCAULT, M.; DREYFUS, H.; RABINOW, P. Apêndice da Segunda Edição (1983). In: DREYFUS, H; RABINOW, P. Michel Foucault: uma trajetória filosófica para além do estruturalismo e da hermenêutica. Tradução de V. Portocarrero, G. G. Carneiro e A. C. Maia. 2. ed. Rio de Janeiro: Forense Universitária, 2013.

HARAWAY, Donna. Antropologia do ciborgue: as vertigens do pós-humano. 2 ed. Belo Horizonte: Autêntica, 2009.

KATZ, J. N. A invenção da heterossexualidade. Tradução de C. Fernandes. Rio de Janeiro: Ediouro, 1996.

LOURO, G. L. Teoria queer - uma política pós-identitária para a educação. Revista Estudos Feministas, Florianópolis, v. 9, n. 2, p. 541-553, 2001.

MOREIRA, A. N. G.; BARBOSA, G. M. O. S. Desafios da gestão escolar sob a ótica de gestores. In: GLAP, G.; GLAP, L. (Org.). Políticas públicas na educação brasileira: gestão e resultados. Curitiba: Atena Editora, 2017.

PERONI, V. M. V. Redefinições no papel do Estado e a política educacional brasileira. Educación y humanismo, v. 13, p. 1-24, 2011.

ROLNIK, S. Enfin qu'y a-t-l derrière à la chose corporelle? In: ROLNIK, S., CORINNE, D. (Org.). Lygia Clark, de l'ouvre à l'événement. Nous sommes le moule. A vous de donner le souffle. Ville de Nantes: Musée de Beaux-Arts de Nantes, p. 9-15, 2005.

SOSSO, A. G.; FRANÇA, F. F. Gestão escolar e diversidade: discussões sobre a prática de um projeto de ensino e pesquisa. Cadernos da Pedagogia. São Carlos, ano 8, v. 8, n. 16, p. 85-97, jan.-jun. 2015. 